\title{
Early Detection of Type 2 Diabetes Among Older African Americans
}

By: Ellen D. Jones, ND, APRN-BC, Laurie Kennedy-Malone, PhD, APRN-BC, and Laurie Wideman, $\mathrm{PhD}$

Jones, E.D., Kennedy-Malone, L. and Wideman, L. 2004. Early Detection of Type 2 Diabetes Among Older African-Americans. Geriatric Nursing 25(1): 24-28.

Made available courtesy of ELSEVIER: http://journals.elsevierhealth.com/periodicals/ymgn

\section{***Note: Figures may be missing from this format of the document}

\begin{abstract}
:
The purpose of this research was to determine whether a group of African Americans who had no diagnosis of type 2 diabetes had elevated blood glucose levels and other risk factors indicative of type 2 diabetes. A convenience sample of 20 African American adults 50 years and older participated in the pilot study. Participants were screened for elevated fasting capillary blood glucose levels and related risk factors such as hypertension, high cholesterol levels, and high body mass index. Frequency data indicated that at least $50 \%$ of participants had capillary glucose levels greater than $110 \mathrm{mg} / \mathrm{dL}$. An overwhelming majority of the participants with elevated glucose levels had one or more other risk factors for type 2 diabetes. Evidence-based practice clearly indicates that an early detection and control of type 2 diabetes can prevent complications and also help prevent coronary artery disease.
\end{abstract}

Article:

There is an abundant amount of recent research that clearly demonstrates the positive effects that early detection and strict glycemic control can have on preventing the complications associated with type 2 diabetes. ${ }^{1-4}$ The American Diabetes Association Clinical Practice Recommendations 2001 state that early detection, along with adequate treatment, has the potential to greatly reduce the side effects and complications from type 2 diabetes. ${ }^{5}$ For this reason, the American Diabetes Association (ADA) advocates screening susceptible populations that include African Americans, especially African American women. The purpose of this research was to determine whether a group of African Americans, who had no previous diagnosis of type 2 diabetes, had elevated blood glucose levels and other risk factors indicative of type 2 diabetes. The participants' ages ranged from 50 to 88 years, and the majority were aged 65 years or older. Participants were living in financially subsidized public and private independent living centers.

\section{BACKGROUND}

Type 2 diabetes is rapidly reaching epidemic proportions in the United States and is considered the fourth leading cause of death. With a prevalence rate of $7.4 \%$ of the total population, the rate of diabetes mellitus is expected to rise to $8.9 \%$ by the year $2025 .{ }^{6}$ It is estimated that nearly 10.3 million Americans have been given a diagnosis of diabetes and as many as 5.4 million cases have remained undiagnosed. The annual cost of treating direct and indirect medical complications is $\$ 90$ billion. ${ }^{6,7}$ Type 2 diabetes accounts for $85 \%$ to $90 \%$ of all cases of diabetes and disproportionately affects the African American population. More than 3 million African Americans, including 8.5\% of African American males and 12.1\% of African American females, 
as compared with $2.5 \%$ to $8.4 \%$ of white Americans, have diabetes. ${ }^{6,7}$ The incidence of type 2 diabetes greatly increases with age. Regrettably, the disease can remain asymptomatic and undiagnosed for many years. During this time, the individual is at significant risk for diseases that are direct results of type 2 diabetes such as retinopathy, nephropathy, and neuropathy. There is also a significant risk for development of diseases associated with the indirect effects of type 2 diabetes, including coronary artery disease, stroke, and peripheral vascular disease. Studies have shown that African Americans are substantially more likely to experience blindness and endstage renal disease and to require lower-limb amputations than those in other populations with a diagnosis of type 2 diabetes. $^{6-9}$

\section{CLINICAL PRESENTATION IN OLDER ADULTS}

One reason type 2 diabetes is often not detected in older adults is that the classic symptoms associated with hyperglycemia are not evident. Older adults often experience decreased thirst; therefore, primary care providers may ex pect classic complaints of thirst, not usual among the very old. In older adults glucose may not be detected in the urine until osmolar glycemic levels are extremely elevated. Symptoms are most often nonspecific, such as confusion, failure to thrive, and incontinence. Older adults with type 2 diabetes may be less obese than their younger counterparts. Many older adults with type 2 diabetes also have hypertension. ${ }^{10,11}$

One should consider type 2 diabetes when examining older adults with skin infection, joint pain, or neuropathies and those with macrovascular and microvascular diseases such as stroke and heart disease. ${ }^{11}$ Identification and treatment of type 2 diabetes will greatly reduce the risk of cardiovascular morbidity and death. ${ }^{12}$ Recent studies also indicate that older adults treated for diabetes may experience improvement in cognition. ${ }^{13}$

\section{SCREENING OLDER ADULTS}

According to the National Health and Nutrition Examination Survey, NHANES 1II, it is estimated that $20 \%$ of the United States population will have type 2 diabetes by the age of 75 years. ${ }^{11}$ Compounding this problem is the fact that the majority of older adults are unaware that they have the disease. ${ }^{11}$ Screening for type 2 diabetes allows detection of the disease when it is still asymptomatic. Appropriate interventions can then be started, which will improve the prognosis. Screening for type 2 diabetes has a greater benefit when it is done to identify those who are more likely to be at risk and when the screening uses measurements that keep costs down. Because the incidence of type 2 diabetes among older African Americans has reached alarming rates with increasingly detrimental outcomes, screening this population appears prudent. Studies have shown that using a fasting capillary whole blood glucose measure by means of a finger stick is the most cost- effective means of conducting a community-wide screen for diabetes. 14,15

The Expert Committee on the Diagnosis and Classification of Diabetes Mellitus (1999) states that a fasting plasma glucose level of $>126 \mathrm{mg} / \mathrm{dL}$ on more than one occasion is needed for the diagnosis of diabetes. Because plasma glucose readings require a sample of venous blood, the majority of screening programs use fasting capillary whole blood glucose readings, which require only a finger stick. Up to $90 \%$ of individuals with diabetes are identified with the use of this method. ${ }^{16}$ It has been shown that a fasting whole blood glucose measurement has a sensitivity of $69 \%$ to $90 \%$ and a specificity of $90 \%$ or greater. However, fasting plasma blood 
glucose levels tend to be $10 \%$ to $15 \%$ higher than whole blood glucose levels. Therefore, fasting capillary whole blood glucose levels have been deemed valid and reliable means of screening. ${ }^{14,15}$ Those with a fasting capillary whole blood level of $\geq 110 \mathrm{mg} / \mathrm{dL}$ should be considered at risk for diabetes and referred for further evaluation. ${ }^{1,17}$ Further, the Expert Committee on the Diagnosis and Classification of Diabetes Mellitus (1999)

Table 1. Seven Major Concepts of the Health Promotion Model and the Study

I. Perceived health status

Health-promoting behaviors such as participation in this study depended on the individual's current state of feeling well or feeling ill.

2. Perceived benefits of behaviors

Participants in the study were inclined to initiate the healthpromoting behaviors because they believed the benefit to be high.

3. Perceived barriers to health-promoting behaviors Because the study was performed within a limited time frame, the participants felt influenced to engage in it.

4. Importance of health

The people who were willing to participate in this study had a higher value of health and were more likely to seek it than those who chose not to participate.

\section{Perceived control of health}

Participants perceived that they had an ability to change their health and this motivated their desire for health.

6. Perceived self-efficacy

The participant's belief that a behavior can influence the occurrence of that behavior.

7. Definition of health

Participants in this study had to have a definition of what health means to them, ranging from the absence of disease to a high level of well-being.

recommends that screenings for diabetes are enhanced when they are done in conjunction with screenings for other risk factors associated with the disease such as high cholesterol levels, hypertension, and obesity. ${ }^{16}$

Results from a recent study indicate that the prevalence of undiagnosed type 2 diabetes among people aged 45 to 65 years is greater among those who have at least three risk factors - primarily obesity, hypertension, and a positive family history of diabetes. ${ }^{10,16}$ Obesity has been identified as a major health concern among all populations in the U.S. Department of Health and Human Services (2000) Healthy People 2010 Objectives. ${ }^{18}$

\section{CONCEPTUAL FRAMEWORK}

Nola Pender's health promotion model, which integrates nursing and behavioral science perspectives, was used as the theoretical basis for this study. ${ }^{19}$ The health promotion model identifies the cognitive-perceptual factors within an individual that are modified by personal, situational, and interpersonal characteristics to result in participation in health-promoting behaviors. The seven major concepts of age, education, gender, income, body weight, family patterns of health care, and expectations of significant others all play a role in determining health care behaviors (Table 1).

\section{METHODS}




\section{Setting and Sample}

A convenience sample was selected from among the total number of residents at two independent living longterm care retirement centers. The majority of residents were African American women with few financial resources. Criteria for inclusion in the study included African American ethnicity, age 50 years or older, no previous diagnosis of diabetes, and the ability to give both written and oral consent. The sample consisted of 20 African American older adults $(\mathrm{N}=20), 4$ men and 16 women. The age range of the female participants was 56 to 88 years with a mean age of 74 years. The age range of male participants was 52 to 90 years with a mean age of 69 years.

\section{Design}

A descriptive correlational study design was used to identify participants who had not been previously given a diagnosis of type 2 diabetes and who had critical risk factors associated with the disease. Recommendations for diabetic screening from the ADA and previous screening studies indicate that screening for type 2 diabetes is most effective when all relevant risk factors are targeted. For this study, the primary risk factor examined was the elevation of fasting capillary whole blood glucose. Included in the study was the identification of other physical characteristics that place participants at increased risk for the disease. Screening also included cholesterol levels, visual acuity, blood pressure readings, examination of feet for neuropathy, pertinent health history information from the ADA's 2000 Diabetes Risk Test Questionnaire, and total body composition assessment indices. ${ }^{1,6}$ Pender's cognitive perceptual factors, ${ }^{19}$ which are outlined as seven major concepts, indicate health-promoting behaviors. These concepts were measured by using participant's overall weight, body mass index, skin-fold metrics, and questions concerning overall preventive health behaviors such as, "When was the last time you visited your primary care provider? Your dentist?" and questions concerning the taking of prescribed medications and exercise patterns.

\section{Procedure}

The human subjects committees of the university and clinical institutions granted approval before the study began. Intensive training in all study procedures and assignment of roles for research nurses followed. The research nurses were graduate nurses in the Adult/Gerontological Nurse Practitioner Program. Two weeks before the initiation of the study, fliers were posted in the retirement centers advertising Diabetes Awareness Day. All residents were invited to attend. Those who attended Diabetes Awareness Day were given information regarding risk factors, signs and symptoms of the disease, and methods to obtain further information. Once this information was presented, the study was explained to the residents. Each resident who met inclusion criteria for the study was invited to participate. Once written consent was obtained, participants were given instructions for the morning of the study. They were required to attend two 45-minute appointments for data collection. Participants 
Table 2. Participants with Risk Factors for Type 2 Diabetes

\begin{tabular}{|c|c|c|}
\hline \multirow[b]{2}{*}{ Risk Factor } & \multicolumn{2}{|c|}{ Sample Size (N = 20) } \\
\hline & Number & Percentage \\
\hline $\mathrm{FBG} \geq 110 \mathrm{mg} / \mathrm{dL}$ & 10 & 50 \\
\hline $\mathrm{BMI} \geq \mathbf{2 7}$ & 8 & 40 \\
\hline Total cholesterol $\geq 200 \mathrm{mg} / \mathrm{dl}$ & dL 10 & 50 \\
\hline $\begin{array}{l}\text { Elevated blood pressure } \\
\text { ADA risk score }\end{array}$ & $\begin{array}{l}11 \\
15\end{array}$ & $\begin{array}{l}55 \\
79\end{array}$ \\
\hline
\end{tabular}

FBG, fasting blood glucose levels. BMI, body mass index; ADA, American Diabetes Association.

Table 3. Frequency of Participants with FBG $\geq 110$ $\mathrm{mg} / \mathrm{dL}$ and Risk Factors for Type 2 Diabetes

$\begin{array}{lc}\text { FBG } \geq 110 \mathrm{mg} / \mathrm{dL}+\text { Risk Factor } & \text { Number } \\ \text { BMI } \geq 27 & 4 \\ \text { Total cholesterol } \geq 200 \mathrm{mg} / \mathrm{dL} & 5 \\ \text { Elevated blood pressure } & 4 \\ \text { ADA risk score } & 9\end{array}$

FBG, fasting blood glucose levels. BMI, body mass index, ADA, American Diabetes Association.

were required to fast the morning of their appointments. Afterward, they were given a written record of their screening results. Those with abnormal screenings were referred to their local primary care provider for further evaluation.

\section{Measures}

A fasting capillary whole blood glucose determination was performed between 8:00 AM and 10:45 AM by the finger-stick method. According to the ADA's 2000 recommendations, participants with a fasting capillary whole blood glucose reading of $>110 \mathrm{mg} / \mathrm{dL}$ were considered to have impaired fasting glucose metabolism. Those participants with glucose levels $>126 \mathrm{mg} / \mathrm{dL}$ were considered to have elevated glucose levels. Participants were given the ADA's 2000 Diabetes Risk Test questionnaire. 1,5 Participants who scored 10 points or higher on the risk test were considered to be at significant risk for type 2 diabetes. Determinations of fasting capillary whole blood triglyceride levels and high-density lipoprotein cholesterol levels were performed between 8:00 AM and 10:45 AM by the finger-stick method. According to the ADA's 2000- 2001 recommendations, fasting capillary whole blood triglyceride readings of $\geq$ $250 \mathrm{mg} / \mathrm{dL}$ and high-density lipoprotein cholesterol readings of $<35 \mathrm{mg} / \mathrm{dL}$ are considered abnormal. Blood pressure was measured, and participants with a blood pressure reading of $\geq$ 140/90 $\mathrm{mm} \mathrm{Hg}$ were considered to have elevated blood pressure. ${ }^{1,5,6}$ Each participant underwent filament screening of both feet and examination of the feet for ulcers and lesions. Total body composition assessments were done by using the Xitron Hydra ECF/ICF multifrequency bioelectrical impedance (B1A) device (Bioimpedance Analyzer 4200; Xitron Technologies, Inc., San Diego, California) and by performing multiple skinfold circumference measurements.

\section{Data Analysis}


Descriptive statistics were used to illustrate the demographics, fasting capillary whole blood glucose levels, and other comorbidity risk factors. Pearson correlation analysis was used to determine the relationships between demographic variables, comorbidity factors, and fasting capillary whole blood glucose levels. Data were analyzed by using the Statistical Packages for the Social Sciences (SPSS 11 [2002] Statistical Analysis; SPSS Inc., Chicago, Illinois).

\section{RESULTS}

Of the 20 participants, 19 had four or more risk factors associated with type 2 diabetes. One of the participants had only one risk factor present, and one participant exhibited seven risk factors. Weight risk ratio, or obesity, was the most commonly detected risk factor. None of the participants were found to have decreased filament sensation or ulcers or lesions on the feet. Ten subjects were found to have fasting blood glucose levels $\geq 110 \mathrm{mg} / \mathrm{dL}$, and five of these participants had levels $\geq 126 \mathrm{mg} / \mathrm{dL}$ - levels indicated for a diagnosis of type 2 diabetes. Of the 10 participants with elevated glucose levels, eight were female and two were male.

Approximately half of the men and women in the sample had elevated blood glucose levels.

Table 2 shows the number of participants who had risk factors for microvascular and macrovascular complications, as well as type 2 diabetes. Ten of the participants were identified as having total cholesterol levels $\geq 200 \mathrm{mg} / \mathrm{dL}$, and six of these participants were taking cholesterol-reducing medications. Twelve participants were identified as having elevated blood pressure, even though all of them were taking prescribed blood pressure medications.

Table 3 shows the number of participants who had elevated fasting blood glucose levels and abnormal cholesterol levels, blood pressure, body mass indexes, or scores on the ADA risk test questionnaire. The number of participants who had elevated fasting blood glucose levels and other comorbidity risk factors was high. Three participants had fasting blood glucose levels $\geq$ $110 \mathrm{mg} / \mathrm{dL}$, cholesterol levels $\geq 220 \mathrm{mg} / \mathrm{dL}$, and blood pressure measurements $\geq 140 / 90 \mathrm{~mm} \mathrm{Hg}$. Of the three participants who indicated that they had a previous myocardial infarction, two were found to have elevated fasting blood glucose levels. However, Pearson's correlations did not reveal statistical significance among the comorbidity risk factors and elevated blood glucose levels.

Mean values for indices of percent body fat were $43.9 \%$ and $39.8 \%$ for women and men, respectively. Sagittal diameter, or abdominal fat measurement, was $33.1 \mathrm{~cm}$ for men and $36.3 \mathrm{~cm}$ for women; measures greater than $25 \mathrm{~cm}$ are considered elevated. Waist circumferences were $102 \mathrm{~cm}$ and $104 \mathrm{~cm}$ for men and women, respectively. Adults 18 years of age and older are considered to have central obesity if waist circumference exceeds $102 \mathrm{~cm}$ in men and $88 \mathrm{~cm}$ in women. Elevated percent of body fat indices and increased saggital diameters and waist circumferences were all indicative of increased risk for heart disease and type 2 diabetes, especially among the female participants.

Responses to questions about personal health care behaviors indicated that $100 \%$ of the participants had visited their primary care provider at least once during the last year. Sixteen participants had visited an optometrist or an ophthalmologist, but only 11 participants had been to a dentist. Only five participants stated that they engaged in routine exercise. However, they all 
stated that they spent at least four hours a day in activities that required either walking or standing.

\section{DISCUSSION AND IMPLICATIONS}

Nearly $100 \%$ of participants had one or more risk factors for type 2 diabetes. Although few subjects exhibited fasting blood glucose levels $>200 \mathrm{mg} / \mathrm{dL}, 50 \%$ had fasting blood glucose levels above ADA 2000 recommended guidelines. These findings are similar to trends described in the literature that suggest that many older adults have undiagnosed hyperglycemia. This study also shows that many older adults have comorbidity risk factors associated with type 2 diabetes. Unfortunately, the comorbidity risk factors were also untreated or treated at subtherapeutic levels. Further, in the majority of cases, primary care providers had not discussed the implications of type 2 diabetes and the need for prevention during the past year.

Although this sample size was small, the findings suggest that among older African Americans with limited resources, little health care screening for type 2 diabetes has been completed. Likewise, this study suggests that among this population, close monitoring of cardiovascular risk factors has not occurred. It is apparent from this study that gerontologic nurses need to continue screening older adults, especially those with risk factors for type 2 diabetes. ADA 2001 recommendations and guidelines clearly indicate that early detection and treatment of type 2 diabetes are the most beneficial means of managing the complications of this disease, especially among older adults. ${ }^{5}$ Because early detection and treatment of type 2 diabetes may also reduce the risk of stroke, heart disease, and peripheral vascular disease, screening for associated risk factors may help reduce the incidence of morbidity and death among older adults. Interventions targeted at modifiable risk factors associated with type 2 diabetes for older adults may also help reduce the incidence of complications from heart disease and stroke.

The majority of participants in this study perceived the importance of their own health, as demonstrated by their frequent health care visits and their willingness to follow medication regimens. However, it is unclear whether this study population understood that they had control over their own health. Gerontologic nurses should continue to reinforce the power of healthy lifestyle behaviors and the impact of individual choices on protection of overall health.

\section{REFERENCES}

1. American Diabetes Association. Position statement: screening for type 2 diabetes. Diabetes Care 2000;23:(Suppl 1):1-32.

2. Agency for Healthcare Research and Quality. AHRQ research on diabetes care. Translating research into practice fact sheet. Department of Health and Human Services, January 2000. Publication No. 00-P018.

3. Centers for Disease Control Diabetes Cost-Effectiveness Study Group. The cost-effectiveness of screening for type 2 diabetes. JAMA 1998;280:1757-63.

4. Florence J, Yeager B. Treatment of type 2 diabetes mellitus. Am Fam Physician [serial online] May 1999. [14 pages]. Available from: www.aafp.org/afp/990515ap/2835.html.

5. American Diabetes Association. Position statement: clinical practice recommendations for standards of medical care for patients with diabetes mellitus. Diabetes Care 2001;24:(Suppl 1):1-184. 
6. American Diabetes Association. Position statement: screening for type 2 diabetes. Diabetes Care 2000;23:(Suppl 10):1451-1597.

7. Agrawal L, Emanuele N, Abraira C, Henderson W, Levin S, Sawin C, et al. Ethnic differences in the glycemic response to exogenous insulin treatment in the Veterans Affairs cooperative study in type 2 diabetes. Diabetes Care 1998;21:510-5.

8. Briscoe VJ, Pichert JW. Evaluation of a program to promote diabetes care via existing agencies in African-American communities. ABNF Journal 1999;10:111-8.

9. Eastman R, Javitt J, Herman W, Dasbach E, Merriman C, Maier W, et al. Models of complications of NIDDM. Diabetes Care 1997;20:735-44.

10. Franse L, Di Bari M, Shorr R, Resnick H, Jacques T, vanEijk J, et al. Type 2 diabetes in older well-functioning people: who is undiagnosed? Data from the Health, Aging, and Body Composition Study. Diabetes Care 2001;24:2065-70.

11. Meneilly G, Tessier D. Diabetes in elderly adults. J Gerontol A Biol Sci Med Sci 2001;56:M5-M13.

12. Tenenbaum A, Motro M, Fishman E, Boyko V, Mandelzweig L, Reicher-Reiss H, et al. Clinical impact of borderline and undiagnosed diabetes mellitus in patients with coronary artery disease. Am J Cardiol 2000;86:1363-6.

13. Edelman D, Edwards L, Olsen M, Dudley T, Harris A, Blackwell D, et al. Screening for diabetes in an outpatient clinic population. J Gen Intern Med 2002;17:23-8.

14. Engelgau M, Narayan K, Herman W. Screening for type 2 diabetes. Diabetes Care 2000;23:1563-79.

15. Khan N, Hershey C. Update on screening for type 2 diabetes. Postgrad Med 2001;109:2734.

16. The Expert Committee on the Diagnosis and Classification for Diabetes Mellitus. Report of the Expert Committee on the Diagnosis and Classification of Diabetes Mellitus. Diabetes Care 1999;22:(Suppl 1):1-180.

17. American Diabetes Association. Position statement: the prevention or delay of type 2 diabetes. Diabetes Care 2002;25:742-9.

18. U.S. Department of Health and Human Services. Healthy People 2010: understanding and improving health. 2nd ed. Washington, DC: U.S. Government Printing Office; Nov 2000.

19. Pender N. Health promotion in nursing practice. 3rd ed. Stamford (CT): Appleton \& Lange; 1996.

Acknowledgments

The authors gratefully acknowledge the School of Nursing Dean's Research Initiative and Sigma Theta Tau, Gamma Zeta Chapter for the research grants to support the study. 